FOCUS ON ...

\title{
Penetrating Brain Injury In Military Conflict: Does It Merit More Research?
}

\author{
W Sapsford
}

\section{Introduction}

One of the primary goals of the military scientist addressing the prevention of trauma, is to develop new concepts for attenuating energy transfer to the body from either penetrating, non-penetrating or blast impacts. Personal armours have deficiencies, both in the body coverage achievable without degrading military performance, and in the inherent ability of the materials to attenuate high energy impacts, particularly from high energy bullets and anti-personnel fragments. Protection of the head from these types of projectiles is a difficult task personal armour materials are available to stop very high energy projectiles (even up to $12.7 \mathrm{~mm}$ bullets), but the weight of these technologies precludes them from use on helmets. It is inevitable, therefore, that practical military helmets cannot stop high energy penetrating projectile impacts; they are remarkably effective however, against the principal threat in war - low energy antipersonnel fragments. The development of practical helmets capable of stopping high energy bullets is constrained by the limitations of currently available materials. Penetrating wounds to the brain continue to be a feature of military conflict.

There are two types of traumatic brain injury (TBI), blunt and penetrating. The mechanisms are very different. Blunt injury involves the coupling of linear and rotational acceleration and deceleration forces into the brain tissue. The resultant impacts of brain tissue within the skull, and the tortional forces in particular, lead to primary brain injury, complicated by secondary damage as a result of subsequent pathological processes. Penetrating brain injury (PBI) involves local forces and stress waves that radiate out from the injury track, especially in the case of high available energy bullet and fragment injury.

What is the status of research into the

Sqn Ldr W Sapsford MA MB BChir FRCS RAF

Honorary Research Fellow

Biomedical Sciences, Defence Science and Technology

Laboratory,Porton, Salisbury, Wiltshire, SP4 0JQ. environment. The established experimental models of TBI understandably focus on severe blunt head injury; this is much more frequent than PBI in a civilian setting. Furthermore, PBI in a civilian environment is different both in the characteristics of injury and outcome to that seen on the battlefield when helmets are frequently worn. Militarily relevant PBI is an underinvestigated field and receives little attention in research laboratories. Indeed, previous models of PBI involving the use of projectiles fired into the brain have succumbed to political pressure following animal rights activism (1).

The aims of this article are to:

- examine the nature and extent of the problem of PBI in the military environment;

- identify the key clinical issues wherein the military scientist may profitably focus research to result in more effective treatment of the brain-injured casualty, particularly in the early stages of the injury;

- provide a clinical basis for new approaches to the protection of the head from high energy penetrating projectiles; specifically, recognising the current inability to stop high energy projectiles and the merit in transforming a high energy transfer penetrating wound to the brain into a low energy transfer wound using lightweight materials.

\section{Ballistic Considerations}

Penetrating brain injury generally results from bullets, munition fragments and low velocity objects such as arrows and knives. Penetration is a function of the available energy of the projectile, and the retardation afforded by the tissues. The retardation transfers energy into the tissues; the energy does work on the tissues resulting in damage. The retardation is a function of the shape of the object (presented area), the angle of approach and the properties of the tissues. Brain injury is further complicated by the generation of secondary bone fragments and multiple metallic fragments from the disrupted casing of the bullet.

Lower available energy projectiles, such as small anti-personnel fragments, arrows and knives create a track of primary tissue damage without substantial gross injury peripheral to the track. Higher available ischaemia and stab wounds, but few address the issues relevant to PBI in the military 
energy projectiles, such as bullets, result in a more complex wounding pattern. A low available energy bullet may transfer sufficient energy to create a permanent track of tissue injury as it penetrates the brain, crushing and lacerating the tissue in its path. Additionally, the bullet will also produce a small temporary cavity, and stress (pressure) waves. High available energy projectiles such as rifle bullets will normally transfer large quantities of energy and produce large temporary cavities, and stress waves of great magnitude. The transfer of energy from the bullet to the tissue occurs radially from the primary track, compressing the tissue tangentially. The temporary cavity rapidly expands, reducing pressure below atmospheric and sucking debris into the wound; it then collapses. The cavity will then undergo several smaller expansions and contractions of diminishing amplitude. Within an inelastic tissue like the brain, the extent of injured tissue may be 10 to 20 times the size of the projectile.

The clinical effect of the temporary cavity on tissues depends upon their mechanical properties, and the function of the tissues. In the case of brain, a notable feature influencing the transfer of energy and the mechanical (and functional) injury is the presence of the cranial vault and base. The formation of a large temporary cavity may devastate the integrity of the vault. The cranial cavity may also reflect stress waves leading to complex and intense pressure fluctuations and shear in the hemispheres and medullary centres.

Handguns generally fire projectiles at or near sonic velocity and are regarded as low available energy weapons compared to rifles that produce projectiles at supersonic velocities and have high available energy. Rifle bullets are also longer and more pointed than handgun rounds; the instability of the bullet consequential to entering tissue such as brain leads to tumbling (yaw). The presented area of the bullet will increase during the yawing cycle, resulting in greater retardation, high energy transfer, and a large temporary cavity. Fragmentation and deformation of the projectile can enhance further the energy imparted to the tissue. Fragmenting rounds create multiple injury tracks. Fragmentation potential is increased by scoring the jacket of the bullet to promote deformation and break-up (Dum-Dums) or by filling the round with pellets (the Glaser round). In order to reduce "superfluous wounding", military bullets are jacketed to inhibit disruption of the projectile (The Hague Peace Conference 1899). For police use, deformation may be enhanced by hollowing the point of the bullet so that it expands on impact, creating a larger permanent wound track, increasing energy transfer and reducing the incidence of perforation of the body ("through and through" wounds).

These ballistic factors explain the span of injuries observed in tissue penetration by a projectile. With low energy transfer, tissue destruction is primarily limited to the track of the missile, whereas high energy transfer rounds destroy much more tissue along and peripheral to the injury track, especially in relatively inelastic tissue, such as the brain.

In practice, high energy transfer wounds to the brain are invariably fatal. However, the division of missiles into high- and lowenergy classes is arbitrary; a broad spectrum of energy levels is delivered to the tissue by high- and low-energy fragments as well as bullets, ricocheting bullets and the penetration of helmets by missiles.

\section{The Nature and extent of PBI}

Penetrating Brain Injury can be defined as any injury where the dura is breached and brain is damaged directly. This may be by the passage of a missile or any other penetrating object, or indirectly by the transfer of energy or local shear caused by, for example, dural penetration by depressed skull fracture. PBI can be differentiated into the following categories:

- Penetrating - a foreign object penetrates skull and dura and remains lodged in the intracranial cavity;

- Tangential - a foreign object glances off the skull, frequently driving bone fragments through the dura into the brain;

- Perforating - a 'through-and-through' injury characterised by both entry and exit wounds. Bone fragments and debris are commonly present within the brain in this class of injury.

The nature of civilian PBI. Civilian PBI can occur as a result of accidents with firearms and other implements but more often it is the result of intentional injury armed conflict or suicide. In this setting, PBI is caused predominantly by firearms. Suicide is the single most common cause of such wounds. A substantial proportion of deaths occurs in the first few hours following injury.

The nature of military PBI. Military PBI results from armed conflict, however, civilian and military armed conflict are significantly different, resulting in dissimilar mechanisms of injury and outcome, especially death. In this setting, and in unprotected troops, penetrating injuries are predominantly caused by shell and mortar fragments. The use of rifles discharging high energy rounds on the battlefield leads to such damaging cerebral injury that the majority of those suffering high energy transfer wounds to the head presumably never reach medical care. The result is that in the military environment, the surviving PBI population is skewed towards those with lower energy fragment wounds. This skewing is further 
accentuated by such moribund severely brain injured casualties receiving a low priority for transport to rear echelon medical care and the prolonged time for evacuation to occur in these hostile environments compared to the civilian environment. Appropriate medical resources available within the first 'golden hour' are negligible. Furthermore, compared to the civilian setting, triage and resuscitation are more difficult, the skill levels of first medical providers is different, the likelihood of wound contamination in battlefield PBI is increased and early treatment facilities are more rudimentary. Additionally, the ability of surviving casualties to reach higher levels of medical care is also compromised. However, PBI in the military setting does occur mainly in young men in excellent physical condition.

Hospital mortality rates of military and civilian PBI. Death rates from PBI are lower for those casualties reaching medical care in the military setting compared to the civilian setting; many military casualties will already have succumbed in the field. The percentage of patients with PBI in hospital who subsequently die is presented in for various conflicts (Table1).

\begin{tabular}{|l|c|c|}
\hline Conflict & $\begin{array}{l}\text { Mortality - percentage of } \\
\text { PBI casualties in hospital }\end{array}$ & Source \\
\hline WWIII & $10-13$ & $(2,3)$ \\
\hline Korea & 10 & $(4)$ \\
\hline Vietnam & 30 & $(5)$ \\
\hline Lebanon & 26 & $(6,7)$ \\
\hline Iran-Iraq & 16 & $(8)$ \\
\hline $\begin{array}{l}\text { The data for the Iran-Iraq war only includes casualties } \\
\text { reaching a tertiary referral centre, a mean of } 49 \text { hours } \\
\text { post-injury. }\end{array}$ \\
\hline
\end{tabular}

Table 1. In-hospital mortality rate for penetrating brain injury.

By comparison, the mortality rate in civilian PBI amongst all-comers admitted to neurosurgical centres varies between 34\% and $79 \%(9-17)$. If patients in the series that had no dural penetration $(11,14)$ and 'mild' injuries (GCS 14-15) (15) are excluded, the mortality rates are uniformly above $60 \%$ for civilian PBI - less die outside medical facilities because they are transported quickly to hospital.

Civilian incidence of PBI mortality. In her reassessment of the epidemiology of trauma deaths in a civilian trauma centre in the US, Sauaia reported that the most common mechanism of death following trauma was penetrating injury at $49 \%$. Gunshot wounds accounted for $42 \%$, stab wounds represented a further $6 \%$ and other objects caused $1 \%$ of penetrating injury (18). The most frequent cause of post-injury death was central nervous system (CNS) injury at $42 \%$ but only $20 \%$ of this CNS injury was the result of craniocerebral penetration, the remainder being blunt trauma. The overall mortality rate for PBI in this civilian study was therefore about $8 \%$.

Of the total of those who died of CNS injury a third (35\%) died before reaching the hospital and of the two-thirds (65\%) who did reach the hospital and died subsequently, almost half $(42 \%)$ had gunshot wounds to the head (18). About 16,500 people die of gunshot wounds to the brain each year in the USA $(19,20)$, approximately half of the total of 33,000 fatal shootings. In two series of civilian patients with PBI that included patients found dead at the scene or on arrival at the hospital, the mortality rate was $83 \%-93 \%$ $(12,21)$. Thus, in a civilian environment where handguns are commonplace (such as in the US) PBI is very often fatal and it accounts for $8 \%$ of all post-injury deaths.

Computed tomography scans (CT) identifying the location of trauma in the brain of those sustaining PBI have enabled an association to be made between the site of PBI and mortality. Twenty three percent die following unilobar injury, $40 \%$ where the mid-sagittal plane is breached, $53 \%$ if the bullet crosses the mid-coronal plane and $75 \%$ if both these mid-planes are crossed. Transventricular injuries are also associated with a high mortality as is fragmentation of the bullet $(7,11,22,23)$. The majority $(80 \%)$ of fatal neurotrauma is, however, blunt and accounts for $34 \%$ of all post-injury deaths.

Military incidence of PBI mortality. It is estimated that TBI, in all its forms, is one of the leading causes of combat injury accounting for $20 \%-25 \%$ of all battle incurred wounds in the modern theatre of war (the leading cause of combat injury is limb injury). Bellamy estimated that $50 \%$ of PBI casualties will die immediately or shortly after wounding (killed in action, KIA). He also estimated that $80 \%$ of those with TBI, surviving to reach medical care, have PBI (24). Of those with craniocerebral injuries who reach medical care, $43 \%$ ultimately die of wounds (DOW) (25). These figures suggest that, of those combatants receiving a TBI, the total mortality rate from PBI is approximately $67 \%$, consisting of the $50 \%$ who are KIA on the battlefield (assuming that they all died of PBI) and the additional $17 \%$ who DOW under medical supervision. The latter figure agrees well with the known fatality rates of between $10 \%-30 \%$ of PBI in various conflicts who are accounted for because they survive to reach medical care (2-8). These figures also compare very favourably to those found in the civilian environment, where the total mortality rate from PBI is between $83 \%-93 \%$ and a "died in hospital rate" of $60 \%$ or more (Table 2 ). 


\begin{tabular}{|c|c|c|c|c|}
\hline Penetrating Brain Injury & \multicolumn{2}{|c|}{$\begin{array}{l}\text { Military } \\
\text { Incurred on the battlefield }\end{array}$} & \multicolumn{2}{|l|}{ Civilian } \\
\hline $\begin{array}{l}\text { Overall Incidence } \\
\text { Percent of all traumatic injuries }\end{array}$ & \multicolumn{2}{|c|}{$20 \%$} & \multicolumn{2}{|l|}{$8 \%$} \\
\hline $\begin{array}{l}\text { Hospital Mortality } \\
\text { Percent of admissions }\end{array}$ & \multicolumn{2}{|c|}{$\begin{array}{l}10-30 \% \\
\text { Died of wounds }\end{array}$} & \multicolumn{2}{|l|}{$60-79 \%$} \\
\hline & $\begin{array}{l}\text { Low available } \\
\text { energy missile }\end{array}$ & $7.5 \%$ & \multirow[t]{2}{*}{$\begin{array}{l}\text { Low available energy } \\
\text { missiles predominantly }\end{array}$} & \multirow[t]{2}{*}{$60-79 \%$} \\
\hline & $\begin{array}{l}\text { High available } \\
\text { energy missile }\end{array}$ & $23-50 \%$ & & \\
\hline Pre-hospital mortality & \multicolumn{2}{|l|}{$\begin{array}{l}50 \% \\
\text { Killed in action }\end{array}$} & \multicolumn{2}{|l|}{$7-17 \%$} \\
\hline $\begin{array}{l}\text { Total Mortality } \\
\text { Percent of all PBI casualties }\end{array}$ & \multicolumn{2}{|l|}{$67 \%$} & \multicolumn{2}{|l|}{$83-93 \%$} \\
\hline
\end{tabular}

Table 2. Estimates of the incidence and mortality of PBI in military and civilian environments.

Whilst it is true that few will survive a perforating, through-and-through PBI and any injury to the head from a high available energy projectile is invariably fatal, many penetrating and tangential PBI injuries with skull and dural penetration, are survivable. Aarabi analysed outcome in 435 casualties suffering PBI with dural penetration from all missiles (low and high-energy) in the IranIraq war who survived to reach a neurosurgery centre (8) (Table 3 ).

\begin{tabular}{|l|c|c|}
\hline $\begin{array}{l}\text { Type of penetrating } \\
\text { brain injury }\end{array}$ & Incidence (\%) & Mortality (\%) \\
\hline Penetrating & 61 & 19.9 \\
\hline Tangential & 29 & 15.6 \\
\hline Perforating & 9 & 48.8 \\
\hline
\end{tabular}

Table 3. Penetrating brain injury type and mortality (from Aarabi (8)).

It is assumed that helmets were available to these combatants in the Iran-Iraq war, but it is not stated whether they were worn or how effective they proved. It is estimated elsewhere that between $23 \%$ and $50 \%$ of high-energy bullet PBI is fatal in those who reach medical care. In the case of low-energy PBI, the hospital fatality rate is estimated at only $7.5 \%(5,26)$.

In combat, involving numerous soldiers (large unit or high intensity fighting), up to $80 \%$ of PBI is caused by low-energy missile injury such as fragments. In some military scenarios, largely involving urban operations or operations against semi-organised pseudomilitary factions (asymmetric warfare), there may be a higher frequency of bullet wounds compared to fragmentation injuries. Thus, in general, there is a high rate of PBI in the military environment $(80 \%-90 \%$ of all TBI), but it is predominantly low-energy in nature $(80 \%$ of all PBI) and caused by fragments and other missiles. Certain operations, however, will expose the soldier principally to high available energy bullets. For the former, a mortality rate of $7.5 \%$ demonstrates a good chance of favourable outcome (in terms of mortality) for the soldier; the same cannot be said for the latter.
The incidence and mortality figures presented here are summarised and shown in Table 2. All the figures are approximate and derived from a number of studies. The table enables a comparison to be made between military and civilian PBI. The high overall mortality in the civilian environment probably results from the high incidence of suicide by gunshot.

If the soldier survives the initial trauma and reaches medical attention (a 50\% chance), he/she then has a $57 \%$ chance of survival following PBI from projectiles, presumably, of lower energy. In other words, up to $30 \%$ of victims of TBI (PBI) survive and will also subsequently lead a reasonable quality of life (27). This bears very favourable comparison to civilian PBI, (but not to civilian TBI that is associated with an $80 \%$ survival rate as it is predominantly blunt trauma), and to the survival rates seen after cardiac arrest outside hospital, $(0.3 \%)$ despite the resources and training devoted to this disease.

\section{The Opportunities To Improve Survival Following PBI}

The majority of deaths occur on the battlefield before evacuation to medical treatment facilities. Bellamy estimates that for every casualty who dies of wounds in a medical treatment facility, up to 9 have already been killed in action. Thus, in order to significantly improve combat casualty care and given optimal circumstances (such as available in Vietnam), the emphasis must be placed on field medical care, or the prehospital phase of patient management by the combat medical technician and subsequently, the staff at the regimental aid post (24). The target should be to improve the care of casualties who become listed as KIA rather than those who are ultimately listed as DOW.

Advances in the composition and design of combat clothing, in particular the helmet, may contribute to a reduction in PBI mortality; they will not eliminate it. Measures to improve forward resuscitation include ensuring that a casualty's airway (A) and breathing (B) are scrupulously maintained 
and the early recognition of haemorrhage (C), either overt, and thus controllable by compression, or incompressible truncal blood loss, and thus uncontrollable without surgical intervention. There has been renewed interest recently in the management of haemorrhage, the most common cause of death in both the civilian and military environments at $50 \%$ mortality of both those found dead at the scene, and those who die subsequently $(18,24)$. Emphasis is now placed on the pre-hospital management of haemorrhage, hypotensive resuscitation protocols and different management strategies based on the need to get those with uncontrolled haemorrhage to surgical treatment as rapidly as possible. There is also research underway in UK, US and Canada to identify and assess novel fluids for resuscitation, such as hypertonic saline dextran (HSD) and liposomally encapsulated haemoglobin-based oxygen carriers that can be deployed in the field. Antishock drugs, such as recombinant activated factor VII may also have a pre-hospital role in arresting uncontrolled haemorrhage acutely, allowing time for rearward evacuation to take place before exanguination occurs. Evacuation delays, pre-treatments and the delivery of medical treatment once in a hospital will also be discussed to evaluate their potential impact on the survival of casualties of PBI.

\section{Prevention - Helmet Design}

There is little work to identify where improvements can be made in the prehospital management of patients with PBI, $50 \%$ of whom die on the battlefield. Physical protection from PBI is plainly an important, but difficult issue. Current helmet compositions and designs and high levels of troop discipline (which ensured soldiers actually wore their helmets during the Gulf conflict) resulted in only one US soldier requiring neurosurgery for a base of skull PBI in the Gulf conflict. This compares favourably to the predicted incidence of four, from the 143 soldiers wounded by missiles (28). In the Vietnam war, the helmet originally designed in WWII was worn, and helmet discipline was poor; $98 \%$ of PBI occurred to the cranial vault (28). Similarly in a series from the Lebanese conflict, $87 \%$ of PBI was craniocerebral injury (7). The Gulf experience represents a dramatic improvement, albeit the number of such casualties was very small.

It is possible that a helmet could be produced from known materials that will prevent TBI or PBI from a high available energy military rifle round. However, the load to the head and neck from the heavy materials such as ceramics that would be required to stop a high energy rifle round preclude general combat issue of such technology. Alterations in design could reduce $\mathrm{PBI}$ from missiles passing beneath the rim into the base of skull (however, the helmet must also allow the soldier to use headphones and other equipment such as respirators). An approach taken with protection of the lower limb from antipersonnel mines is to recognise that for wearable footwear, total protection is not achievable. The strategy is to use materials to attenuate the energy sufficiently to reduce the clinical impact of the trauma, both acutely, and with regard to remaining function. Could such an approach be taken with PBI? Should we recognise that with current materials, absolute protection is not achievable, and the target should be to further reduce energy transfer? Transposing a high energy wound into a low energy one by dissipating energy in the helmet penetration process could significantly increase the potential for survival to reach medical care.

\section{Pre-Hospital Management- ABCs}

There has also been a revolution in the field management of battlefield casualties with the widespread adoption of the principles of PreHospital Advanced Trauma Life Support (PHTLS) (29) and Advanced Trauma Life Support (ATLS) (30) within the military. In the British armed forces, these principles have been incorporated into the Battlefield Advanced Trauma Life Support (BATLS) course (31), directed specifically at the first responders - the Combat Medical Technicians. All these protocols are characterised by emphasis placed on the maintenance of the airway and breathing in the immediate post-injury period and this is likely to have as huge an impact on the outcome of casualties suffering from PBI as any other single change. The opportunity to improve overall survival of PBI casualties therefore exists by improving the first aid skills of the soldier, and management of the airway and breathing by the first medical attendants (especially tracheal intubation). It remains to be seen whether the salvage of potentially moribund PBI casualties by the application of these principles should even be attempted on the battlefield as many will inevitably die when such care must eventually be abandoned as futile.

TBI is frequently associated with haemorrhage from other bodily regions. In the US civilian environment, $35 \%$ of patients with severe TBI are hypotensive on initial presentation and these patients demonstrate twice the mortality and a significant increase in morbidity compared to non-hypotensive patients (32). It is likely that this association is more frequent in the military environment with the preponderance of penetrating injuries over blunt trauma. The attention to appropriate resuscitation in the field, the development of better fluids for resuscitation 
and the application of the adjuncts to resuscitation, such as recombinant activated factor VII, may well have a significant secondary impact on survival following PBI.

Traditionally, patients with TBI are aggressively resuscitated with large volumes of crystalloid with the goal of rapid volume expansion to restore the blood pressure to normal, baseline levels (33). However, recent laboratory studies and a single clinical study have demonstrated that aggressive fluid resusci-tation in the presence of uncontrolled haemorrhage from trauma results in an increase in haemorrhage volume and greater short-term mortality compared to a regimen of limited, hypotensive resuscitation or no resuscitation (34-38). As a result, some investigators recommend that the resuscitation of trauma patients be limited (or maintained at hypotensive levels) until surgical control is achieved, thereby converting the uncontrolled into controlled haemorrhage. Aggressive resuscitation can then be started with the aim of achieving physiologically normal baselines. This policy has been adopted by the British military in their Battlefield Advanced Trauma Life Support manual (31).

Research is underway into the use of such hypotensive resuscitation regimen in combined models of TBI and uncontrolled haemorrhage to establish whether this approach is appropriate in these patients, due to the risk of exacerbating the secondary brain insult by hypotensive resuscitation (39). There are also laboratory studies underway to evaluate TBI and haemorrhage with potentially protective drugs (personal communication) and the potential benefits of HSD for resuscitation in TBI (40-44). Finally, research is taking place in related areas, such as the use of HSD as the initial fluid of resuscitation following blast and haemorrhage (both controlled and uncontrolled). As the science of resuscitation in traumatic uncontrolled haemorrhage develops, so research into the impact of potentially beneficial resuscitation regimen on concomitant military trauma, such as blast and penetrating brain injury, must follow, just as it does in civilian TBI.

In summary, the prompt institution of supportive care by the principles set out in the PHTLS, ATLS or BATLS and attention to resuscitation of casualties with haemorrhage and PBI may improve the outcome of this serious injury.

\section{Evacuation Delays To Medical Care}

The longer that the severely injured casualty remains on the battlefield, the greater the probability of death and therefore of being classified as "killed in action" (KIA). Bellamy analysed the effect of evacuation times on the KIA rates in several conflicts (24). In WWII, the probability of being KIA by any given wound was greater than in the Korean War. This was most likely to be due to the reduced evacuation times in the latter conflict - two to four hours as opposed to six to eight hours in WWII. In Vietnam, the evacuation time was reduced further to one to two hours and the percentage of casualties who received a severe injury and died before evacuation was $20 \%$. The British further reduced evacuation times in Salalah, Oman in 1972-1973 and the number of similarly injured Omani casualties who died was $10 \%$ (albeit the numbers in this conflict are small). Bellamy predicts that the KIA rate will be $20 \%$ if evacuation occurs within the "golden hour", $26 \%$ if evacuation occurs within the militarily relevant "golden six hours" and $32 \%$ if evacuation is delayed to 24 hours (24). In more recent warfare, the evacuation time has been longer than that seen in Vietnam. In the Gulf War in 1991, the median injury to admission interval was 4.41 hours during the ground offensive (45), in Afghanistan in $2001-2$, this delay increased to 8 hours (personal communication). In the Falklands conflict the evacuation delay was as long as 16 hours (personal communication).

PBI requires the evacuation of casualties to rearward specialist neurosurgical units to improve the survival of these severely injured patients. This is reflected in epidemiological statistics which show that, whilst haemorrhage from all causes is responsible for most early deaths following admission to a trauma centre, TBI is a major cause of late death (greater than 48 hours following admission), second only to multiple organ failure (18). By comparison, there are very few deaths from haemorrhage at this stage.

\section{Pre-treatments}

Very little experimental research into penetrating brain injury has been undertaken, despite the serious problem it presents both to military personnel and civilians. Investigators have consistently shown that PBI causes profound cardiorespiratory effects. Indeed the first to report these effects was Horsley in 1894 (46). He noted a transient apnoea following a side-toside cerebral injury with a pistol and attributed this to a 'hydrodynamic effect' on the tissue of the brain that increased the extent of the injury beyond the projectile diameter. This 'hydrodynamic effect' is comparable to the result of a bullet fired at a tin can. If the tin is empty, small entry and exit holes are seen; if it is full of water, the tin will explode. Crockard $(47,48)$ investigated a similar, more controlled injury in primates. He produced a 'clean' wound, away from vital structures and major blood vessels, thus avoiding obfuscating haematoma development and skull fragment penetration and permitting a study of the generalised 
intracranial results of missile injury. $\mathrm{He}$ noted a bradypnoea or transient apnoea after impact, depending on the kinetic energy of the missile, a prolonged bradycardia lasting between 10 to 30 minutes and a period of hypotension for a few minutes following injury. In the higher kinetic energy group, apnoea requiring immediate ventilatory support and more profound bradycardia and reduction in blood pressure were observed. Crockard argued that these effects were due to the 'hydrodynamic effect' of the missile being directly relayed to the structures around the third ventricle and midbrain.

Subsequent workers $(20,49)$ demonstrated similar results and drew similar conclusions. Carey (20) discussed the pressures induced by a missile in water and tissue. $\mathrm{He}$ described: 1) an extremely high juxta-missile pressure, immediately in front of and at right angles to the missile, responsible for tissue destruction along its path; 2) kinetic energy transfer, creating the temporary cavity behind the missile; and 3) a longitudinal 'strong shock' (stress) wave pressure. The latter is a steeply rising, extremely brief (lasting in the region of $10 \mu \mathrm{sec}$ ), highpressure compression front that moves spherically away from the strike point of the missile at approximately the speed of sound in brain tissue.

A shock (or more accurately stress wave) propagating through tissues is the same phenomenon seen in primary blast injury. There are two critical determinants of survival following primary blast: the pulmonary injury and the acute cardiorespiratory responses. Guy $(50,51)$ demonstrated a reflex triad of apnoea, bradycardia and hypotension following moderate thoracic primary blast injury in a rat model and showed that is not evident following blast injury to the abdomen. He proposed that the responses were reflex in nature, as they are not instantaneous, and that the apnoea and bradycardia can be prevented by bilateral vagosympathectomy. He further postulated that one possible pathway is the reflex elicited by pulmonary afferent C-fibres (pulmonary J-receptors), activation of which produces the triad of apnoea, bradycardia and hypotension. Currently unpublished work for the Ministry of Defence, in which various pharmacologic interventions were used as pre-treatments to try to favourably influence the physiological triad, showed that blockade of the known chemical transmitters in the pulmonary C-fibre did not influence the physiological triad. This work demonstrated that: 1) bilateral cervical vagosympathectomy abo-lished the apnoea and bradycardia and attenuated the hypotension; 2) atropine only attenuated the bradycardia; 3) peripherally administered ondansetron (a 5-HT3 antag-onist which interacts with 5-HT activated pulmonary Cfibre afferents) did not modify the response to thoracic blast; 4) centrally administered methiothepin (a central 5-HT IAIC $_{\text {receptor }}$ antagonist) potentiated the apnoea and bradycardia and led to an early death. Further work demonstrated that a centrally acting and centrally administered 5-HT agonist, 5-carboxamidotryptamine (5-CT) as a pre-treatment attenuated the bradycardia seen following primary thoracic blast and that the respiratory stimulant doxopram significantly reduced the duration of apnoea. This series of studies suggested that the reflex elicited by thoracic blast and that elicited by pharmacological stimulation of pulmonary afferent C-fibres does not share a common central nervous pathway. The work indicated that another as yet unknown afferent pathway is activated by primary thoracic blast. What is not in doubt is that the higher centres influence the response of a model to primary blast injury.

Sarphie has shown fissures in the floor of the fourth ventricle in rats following a penetrating injury of the sensorimotor cortex (52). The respiratory and cardiovascular centres in the rat brain stem are just beneath the floor of the fourth ventricle and the conclusion drawn was that these fissures damaged the brain stem respiratory and cardiovascular centres causing the physiological triad of apnoea, bradycardia and hypotension demonstrated in PBI. The rat model subjected to primary blast injury to the thorax in the experiments had no head protection. It is conceivable that the blast waves could affect the cardiorespiratory brain centres in a similar manner to the stress waves that occur in PBI, either directly, or via transmission of the stress waves from the chest to the CSF and the brain. If so, brain stem damage from blast waves might influence the physiological triad of responses that occurs following primary blast injury. However, since the apnoea and bradycardia following a blast injury are abolished by bilateral vagotomies, the most important effects are mediated via the yet to be elucidated afferent pathway from the chest.

If similar brain stem damage occurs following blast injury as has been demonstrated in PBI, there is an opportunity for research into treatments to abolish the apnoea, bradycardia and hypotension following PBI, just as has occurred in primary blast injury research. In particular, if the apnoea could be abolished or attenuated, this may lead to a significant improvement in survival both following PBI and primary blast injury. It has already been demonstrated that the central respiratory stimulant doxapram, peripherally administered within seconds of a primary blast injury to the chest, was able to stimulate respiration and significantly reduced the period of apnoea. It also attenuated the hypotension somewhat. Veterinary surgeons use a soluble form of doxapram that dissolves 
on the tongue to stimulate respiration in neonatal lambs. Could this type of approach be useful in PBI?

Carey (20) argues that following PBI, the integrity of the medullary centres is the predominant factor in determining whether an individual lives or dies, provided excessive intracranial bleeding does not occur. The energy transfer of the missile may determine whether apnoea occurs and its duration, ultimately causing death where the medullary centres are irreversibly damaged. Some casualties who have sustained hemispherical brain damage and are rendered temporarily apnoeic may possibly be saved by prompt respiratory support (the aforementioned principles of first aid and the $\mathrm{ABC}$ of resuscitation) and respiratory stimulants, either as pre-treatments or as post-injury therapies administered in the field. Such pre-treatments or acute respiratory support would raise notable logistic, operational and doctrinal issues. Current practice should not inhibit a review of the benefits of reversing the inevitable apnoea from PBI and blast injury.

\section{Post Admission To Definitive Medical Care}

There is scope to reduce the mortality from PBI once a casualty is delivered to definitive medical care. Definitive medical care, in this context, refers to a field hospital where the full protocol of the ATLS can be delivered, including definitive haemorrhage control, CT scanning and surgical decompression and debridement of intracranial lesions. Mortality from PBI in this setting is, however, frequently the result of a formal declaration of brain death and also from other conditions that subsequently complicate the management of any severely injured casualty, such as sepsis and multiple organ failure; thus these deaths do not apply specifically to PBI. It is conceivable that some of those dying of wounds in the PBI category could be salvaged by improved surgical and/or anaesthetic management of those casualties dying from sepsis and multiple organ failure. These are traditionally areas of interest amongst intensive care physicians and surgeons and a large fraction of trauma research funding is already spent on these problems. Nevertheless complete salvage of these casualties would only have a modest impact on combat casualty care as sepsis and/or organ failure currently cause only two to three percent of total combat mortality (24).

\section{Summary}

The foregoing suggests that there is merit in research into protection of the head from high available energy projectiles, and in some aspects of the management of penetrating brain injury.
Protection: The current composition and design of helmets (supported by a doctrine of use) have already had a substantial impact on PBI from low energy projectiles and some bullets. A wearable helmet capable of stopping high available energy projectiles remains elusive. However the very different survival rates following penetrating brain injury by high energy compared to a lowenergy missiles (50\% and $7.5 \%$ respectively) suggest that improvements in helmet design to convert high energy projectiles to the helmet into low energy wounds to the head may significantly improve survival following PBI.

Medical management: There has already been a revolution in the field of first aid and the skills of first medical responders following the introduction of the principles of ATLS in the late 1970's - a 'gold' standard of trauma care. These principles have since been widely disseminated through courses, such as ATLS, PHTLS and BATLS. Prompt assessment and maintenance of the airway and breathing in a casualty following PBI is likely to be the most important intervention in their survival.

Haemorrhage management is undergoing a major review. It seems likely that the standard ATLS guidelines - that all casualties who are shocked following trauma, should receive a bolus of two litres of crystalloid (or $20 \mathrm{~mL} / \mathrm{kg}$ ) rapidly - will change to incorporate the concepts of hypotensive resuscitation, especially in the case of noncompressible haemorrhage into a body cavity. This recognises the need for rapid evacuation to surgical care where haemorrhage can be definitively controlled. The management of TBI is also following suit. A casualty, dying from poorly managed uncontrolled haemorrhage, is less likely to survive a TBI, as hypotension contributes to secondary brain injury, and consequently significantly increases mortality. There is also interest in novel fluids of resuscitation, such as small volume hypertonic solutions of saline (HSD) and haemoglobin-based oxygen carriers, and pharmacological agents with the potential to arrest non-compressible haemorrhage such as recombinant activated factor VII. The impact of these developments in fluid resuscitation on the management of blunt brain injury is being reviewed; should this not also be extended to penetrating brain injury?

Logistical considerations determine the delay in evacuation of an injured soldier to medical care. Ideally the gold standard of less than one hour should apply, as in civilian practice, but this is rarely possible. In Vietnam, evacuation delays of a little as one hour were possible and TBI casualties were often transferred directly to a neurosurgical centre. Hammon states that this rapid evacuation helped save countless lives and 
preserved function, although it also increased the number of near-terminal patients who died within minutes (5).

Pre-treatments have been studied in primary blast injury, some of which show the potential to reduce the potentially harmful effects of the physiological responses, though no fully satisfactory pre-treatment has been identified yet. Similar patterns of response occur in PBI. In the case of PBI the physiological response is likely to be caused by stress waves influencing medullary areas important in cardiorespiratory control. In the case of thoracic blast injury the response is reflex, with a vagal afferent pathway, although a contribution from a stress wave in the medulla cannot be excluded. However, since both responses to PBI and primary blast injury (to the thorax) involve the same efferent pathways there is scope for interaction between these responses. Thus a model of primary blast injury to the brain may be useful in modelling PBI and pretreatments may be equally effective in both situations. Experimental models of primary blast injury already exist and a model of PBI should be developed to compare and contrast the physiological responses, especially the apnoea, and relate the doseresponse of PBI and primary blast injury to brain stem damage. This may demonstrate some common pathways and/or interactions between PBI and primary blast injury. Control of apnoea is probably the principal intervention that can make a difference in reducing the mortality from $\mathrm{PBI}$.

\section{Conclusions}

In the opinion of this author PBI does merit more research. There are three particular areas where research in this area may benefit a PBI casualty. Research into concepts for further attenuating the impact of highenergy military rifle bullets to the helmet to produce only low available energy wounds to the head may reduce the number of soldiers who are killed in action from PBI. This strategy would recognise that stopping a high available energy rifle bullet is not possible with lightweight helmet designs and that low available energy transfer wounds have a higher incidence of survival than those with high available energy transfer.

Research into a model of PBI could also be utilised to investigate the similarities and differences between the physiological and pathological responses to PBI and thoracic blast injury, in particular the apnoea seen following both injuries. Such a model may facilitate the development of strategies and/or pre-treatments to attenuate the deleterious effects of the pathophysiological responses to these injuries and especially to abolish or reduce the apneic period.

Finally, a model of penetrating brain injury should be developed to study the effects of the recent developments in haemorrhage management on penetrating brain injury, similar to those currently in use to investigate the effect of controlled and uncontrolled haemorrhage on traumatic brain injury.

\section{References}

1. Carey ME. Political interference with research? fAMA. 1991; 266: 3285-3286 (Letter in reply).

2. Small JM, Turner EA. A surgical experience of 1200 cases of penetrating brain wounds in battle, NW Europe, 1944-1945. Br J Surg. 1947; War Surgery Supplement I: 62-74.

3. Meirowsky AM. Penetrating wounds of the brain. In: Coates JB Jr, Meirowsky AM. (eds). Neurological Surgery of Trauma. Washington DC: Office of the Surgeon General. 1965; pp 103-130.

4. Matson DD. In: The treatment of acute craniocerebral injuries due to missiles. Springfield IL: Charles C Thomas; 1948

5. Hammon WM, Kempe LG. Analysis of 2187 consecutive penetrating wounds of the brain from Vietnam. F Neurosurg. 1971; 34: 127-131.

6. Brandvold B, Levi L, Feinsod M, George ED. Penetrating craniocerebral injuries in the Israeli involvement in the Lebanese conflict, 1982-1985: analysis of a less aggressive surgical approach. $\mathcal{f}$ Neurosurg. 1990; 72: 15-21.

7. Levi L, Borovich B, Guilburd JN, et al. Wartime neurosurgical experience in Lebanon, 1982-85, I: penetrating craniocerebral injuries. Isr $\mathcal{F} \mathrm{Med} S \mathrm{Sci}$. 1990; 26: 548-554.

8. Aarabi B. Surgical outcome in 435 patients who sustained missile head wounds during the Iran-Iraq war. Neurosurgery. 1990; 27: 692-695.

9. Byrnes DP, Crockard HA, Gordon DS, Gleadhill CA. Penetrating craniocerebral missile injuries in the civil disturbances in Northern Ireland. $\mathrm{Br} f$ Surg. 1974; 61: 169-176.

10. Clark CW, Muhlbauer MS, Watridge CB, et al. Analysis of 76 civilian craniocerebral gunshot wounds. $\mathcal{F}$ Neurosurg. 1986; 65: 9-14.

11. Grahm TW, Williams FC Jr, Harrington T, Spetzler RF. Civilian gunshot wounds to the head: a prospective study. Neurosurgery. 1990; 27: 696-700.

12. Hernesniemi J. Penetrating craniocerebral gunshot wounds in civilians. Acta Neurochir (Wien). 1979; 49: 199-205.

13. Jacobs DG, Brandt CP, Piotrowski JJ, McHenry CR. Transcranial gunshot wounds: cost and consequences. Am Surg. 1995; 61: 647-654.

14. Kaufman HH, Levi ML, Stone JL, et al. Patients with Glasgow Coma Scale scores 3,4,5 after gunshot wounds to the brain. Neurosurg Clin North Am. 1995; 6: 701-714.

15. Kennedy F, Gonzales P, Dang C, Flemming A, Sterling-Scott R. The Glasgow Coma Scale and prognosis in gunshot wounds to the brain. $\mathcal{F}$ Trauma. 1993; 35: 75-77.

16. Shaffrey ME, Polin RS, Phillips CD, et al. Classification of civilian craniocerebral gunshot wounds: a multivariate analysis predictive of mortality. F Neurotrauma. 1992; 9(suppl 1): S279S285.

17. Suddaby L, Weir B, Forsyth C. The management of .22 calibre gunshot wounds of the brain: a review of 49 cases. Can $\mathcal{F}$ Neurol Sci. 1987; 14: 268-272.

18. Sauaia A, Moore FA, Moore EE, et al. Epidemiology of trauma deaths: a reassessment. $\mathcal{F}$ Trauma. 1995; 38: 185-193.

19. Jagger J, Dietz PE. Death and injury by firearms: who cares? fAMA. 1986; 255: 3143-3144 (Letter).

20. Carey ME, Sarna GS, Farrell JB, Happel LT. Experimental missile wound to the brain. $\mathcal{f}$ Neurosurg. 1989; 71: 754-764.

21. Siccardi D, Cavaliere R, Pau A, et al. Penetrating craniocerebral missile injuries in civilians: a retrospective analysis of 314 cases. Surg Neurol. 1991; 35: 455-460. 
22. Nagib MG, Rockswold GL, Sherman RS, et al. Civilian gunshot wounds to the brain: prognosis and management. Neurosurgery. 1986; 18: 533-537.

23. Aldrich EF, Eisenberg HM, Saydjari C, et al. Predictors of mortality in severely head-injured patients with civilian gunshot wounds: a report from the NIH traumatic coma data bank. Surg Neurol. 1992; 38: 418-423.

24. Bellamy RF. The causes of death in conventional land warfare: implications for combat casualty research. Mil Med. 1984; 149: 55-62.

25. Arnold K, Cutting RT. Causes of death in United States military personnel hospitalised in Vietnam. Mil Med. 1978; 143: 161-164.

26. Carey ME. Learning from traditional combat mortality and morbidity data used in the evaluation of combat care. Mil Med. 1987; 152: 613.

27. Salazar AM, Schwab K, Grafman JH. Penetrating injuries in Vietnam War. Traumatic unconsciousness, epilepsy and psychosocial outcome. Neurosurg Clin N Am. 1995; 6: 715-726.

28. Carey ME, Joseph AS, Morris WJ, et al. Brain wounds and their treatment in VII corps during operation Desert Storm, February 20 to April 15, 1991. Mil Med. 1998; 163: 581-586.

29. Prehospital Trauma Life Support Committee of the National Association of Accident and Emergency Technicians in Cooperation with the Committee on Trauma of the American College of Surgeons. PHTLS Basic and Advanced Prehospital Trauma Life Support. 4th Ed. St Louis, Missouri. Mosby. 1999.

30. Committee on Trauma of the American College of Surgeons. Advanced Trauma Life Support for Doctors - Course Manual. 7th Ed. Chicago Illinois. American College of Surgeons. 1997.

31. Army Medical Directorate [Resources and Plans]. Battlefield Advanced Trauma Life Support. 2nd Ed. 2000.

32. Chesnut RM, Marshall LF, Klauber MR, et al. The role of secondary brain injury in determining outcome from severe head injury. J Trauma. 1993; 34: 216-222.

33. Joint Section on Trauma and Critical Care of the American Association of Neurological Surgeons and the Brain Trauma Foundation: Guidelines for the management of severe head injury. Park Ridge, IL: American Association of Neurological Surgeons, 1995.

34. Bickell WH, Bruttig SP, Millnamow GA, et al. The detrimental effect of intravenous crystalloid after aortotomy in swine. Surgery. 1991; 110: 529-536.

35. Bickell WH, Wall MJ, Pepe PE, et al. Immediate versus delayed fluid resuscitation for hypotensive patients with penetrating torso injuries. $N$ Eng $\mathcal{F}$ Med. 1994; 331: 1105-1109.

36. Gross D, Landau EH, Klin B, et al. Quantitative measurement of bleeding following hypertonic saline therapy in "uncontrolled" haemorrhagic shock. F Trauma. 1989; 29: 79-83.
37. Stern SA, Dronen SC, Birrer P, et al. Effect of blood pressure on haemorrhage volume and survival in a near-fatal haemorrhage model incorporating a vascular injury. Ann Emerg Med. 1993; 22: 155-163.

38. Stern SA, Dronen SC, Wang X. Multiple resuscitation regimens in a near-fatal porcine aortic injury haemorrhage model. Acad Emerg Med. 1995; 2: 89-97.

39. Stern SA, Zink, BJ, Mertz M, et al. Effect of initially limited resuscitation in a combined model of fluidpercussion brain injury and severe uncontrolled haemorrhagic shock. F Neurosurg. 2000; 93: 305314.

40. Walsh JC, Zhuang J, Shackford SR. A comparison of hypertonic to isotonic fluid in the resuscitation of brain injury and haemorrhagic shock. 7 Surg Res. 1991; 50: 284-292.

41. Shackford SR. Effect of small-volume resuscitation on intracranial pressure and related cerebral variables. F Trauma. 1997; 42(suppl 5): S48-S53.

42. Berger S, Schurer L, Hartl R, et al. Reduction of post-traumatic intracranial hypertension by hypertonic/hyperoncotic saline/dextran and hypertonic mannitol. Neurosurgery. 1995; 37: 98107.

43. Berger S, Schurer L, Hartl R, et al. $7.2 \% \mathrm{NaCl} / 10 \%$ dextran 60 versus $20 \%$ mannitol for treatment of intracranial hypertension. Acta Neurochir Suppl. 1994; 60: 494-498.

44. Hartl R, Medary MB, Ruge M, et al. Hypertonic/hyperoncotic saline attenuates microcirculatory disturbances after traumatic brain injury. F Trauma. 1997; 42(suppl 5): S41-S47.

45. Leedhan CS, Newland C, Blood CG. A descriptive analysis of wounds among U.S. Marines treated at second-echelon facilities in the Kuwaiti theatre of operations. Mil Med. 1993; 158: 508-512.

46. Horsley V. The destructive effects of projectiles. Proc $R$ Institution. 1894; 14: 228-238.

47. Crockard HA, Brown FD, Johns LM, Mullan S. An experimental cerebral missile injury model in primates. J Neurosurg. 1977; 46: 776-783.

48. Crockard HA, Brown FD, Calica AB, et al. Physiological consequences of experimental cerebral missile injury and the use of data analysis to predict survival. $\mathcal{F}$ Neurosurg. 1977; 46: 784-794.

49. Levett JM, Johns LM, Replogle RL, Mullan S. Cardiovascular effects of experimental cerebral missile injury in primates. Surg Neurol. 1980; 13: 59-64.

50. Guy RJ, Kirkman E, Watkins PE, Cooper GJ. Physiologic responses to primary blast. $\mathcal{F}$ Trauma. 1998; 45: 983-987.

51. Ohnishi M, Kirkman E, Guy RJ, Watkins PE. Reflex nature of the cardiorespiratory response to primary thoracic blast injury in the anaesthetised rat. Experimental Physiology. 2001; 86: 357-364.

52. Sarphie TG, Carey ME, Davidson JF, Soblosky JS Scanning electron microscopy of the floor of the fourth ventricle in rats subjected to graded impact injury to the sensorimotor cortex. J Neurosurg. 1999; 90: 734-742. 